Paper

\title{
Reasonable Lighting Factors for Work Environment with VDT Tasks
}

\author{
Mitsuyuki KAWAKAMI, Shuichi MATSUMOTO \\ Tokyo Metropolitan Institute of Technology \\ Osamu MYODO \\ Mitsubishi Electric Lighting Corporation \\ Paper ordinally published in Japanese in J.IEIJ, Vol.83-No.5, 1999
}

\begin{abstract}
This paper presents a proposal to design factors for a reasonable lighting environment in Visual Display Teminal(VDT) work, by monitoring changes in the lighting environment by general illumination and partial illumination as a factor of the working environment. We also considered that this factor affects productively and workload from an experimental approach. Since we think that it is not enough to evaluate a lighting environment only by subjective appraisal, we used brain waves as a physiological index for evaluating human mental activity objectively. The evaluation index used in the experiment were obtained by measuring working efficiency and working quality in VDT work, mental changes (stability) recorded by an electroencephalograph (EEG), and determined the workload by a survey of subjective symptoms and by measuring eye fatigue. The results enable us to derive a relationship between reasonable lighting environment and illuminance. The results show the following: 1)When the partial illumination was given to subjects, it was shown to effect their concentration on work and mentally stabilize at the ratio of sumound illuminannce to horizontal illuminance was about 0.05 . 2)When the ratio of surround illuminance to horizontal illuminance was the same, the effect showed remarkable at the ratio of vertical illuminance to horizontal illuminance was lower.
\end{abstract}

\section{Introduction}

Human beings have what are known as the five senses: sight, hearing, touch, taste, and smell. Of these, the sense of sight is the most important source of information for human tasks. It can easily accommodate a lot of stimuli, and it is used a great deal in daily life. In recent years, it has become possible to influence people through the sense of sight by a technology that sends a message to the subliminal consciousness of the receivers by mixing signals at a level that can not be perceived consciously (subliminal technology).

It is a well known fact that work efficiency has been promoted by the introduction of office automation equipment in almost all offices nowadays, and that conventional man-power dependent tasks have shifted to tasks in which the VDT (Visual Display Terminal) tasks are the core. VDT tasks exemplify work that causes eye fatigue, and are characterized by severely restricted working posture and a high level of concentration compared to other tasks. Although it contributes to an increase in productivity, it also causes an increase in the workers' workload, which results in combined physical and mental strains, which in turn may create psychosomatic disorders. Also, since the workers watch the CRT (Cathode Ray Tube) displays for a long time while doing tasks such as voucher and document data input, and information searching via the keyboard, it is considered that there are more complaints of asthenopia (eyestrain with headache and dimming of vision) such as eye fatigue than there are with conventional office tasks. Thus, there have been many studies on adaptability of the man-machine system related to VDT tasks 1) 2).

Lighting and thermal conditions as factors for visual discomfort have been paid attention to ${ }^{3)}$, and also veiling reflections and severe mirror reflections from the VDT display surface that reduce the luminance contrast of the display have been recognized as factors to which attention should be paid.

In the studies so far, it has been found that an even illuminance distribution in which the surrounding illuminance is close to the work plane illuminance is a desirable lighting condition for trouble-free regular tasks in the office. On the other hand, a study has also been done on different surrounding illuminance conditions in which cases were identified in which a lower surrounding illuminance is more suitable for certain kinds of tasks ${ }^{4}$ ).

Although there have been many evaluation experiments in which subjective evaluations such as questionnaires and so on were key in the past, studies to appraise men's psychological reactions through objective evaluations by measuring physiological reactions have been actively made these days owing to the progress in the measuring equipment in recent years. For example, the beating of the heart for the intensity of workload, the electroencephalogram ( $\alpha$ wave) for comfort, and the electric potential related to phenomena (P300) for attention and concentration can be enumerated. However, experimental evaluations measuring the $\alpha$ wave have principally adopted the generated level of 
the wave before and after the workload as an indicator for evaluation, and it is considered that not many experiments have used the temporal measurement and analysis of $\alpha$ waves during tasks $s^{5}$.

Hence, experiments will be implemented in this study regarding the influence on the subjects of the illuminance in the surrounding of the work area (surround illuminance), the illuminance in the work area (horizontal plane illuminance), and the illuminance of the display (vertical plane illuminance) in the environment in which ambient lighting and localized task lighting are used in the VDT work (calculation tasks), and discussion will be made of the appropriate environmental factors for the tasks. The evaluation indices for the experiment were (1) productivity (work efficiency and quality of work) and (2) workload as measured by electroencephalogram during the tasks, by measuring eyestrain (the distance of the adjusted near point, tension period, relaxation period (6) 7), and by the complaint ratio of the subjective symptoms of fatigue.

\section{Experimental Methods}

\subsection{Design of the Experimental Laboratory}

The experiment was carried out in an experimental laboratory $7.5 \mathrm{~m}$ wide, $12 \mathrm{~m}$ deep, and $3 \mathrm{~m}$ high, as shown in Fig. 1. Twenty-six luminaires with two $36 \mathrm{~W}$ fluorescent lamps were installed in the ceiling. The layout of the work area is shown in Fig. 2, and the experimental situation is shown in Fig. 3.

\subsection{Experimental Procedure}

The task that was the object of the experiment was to have the experimental subject add and subtract three digit numbers that were shown on the CRT display, of which an example is shown in Fig. 4, and to have the subjects input the answers via the keyboard while in a sitting position, as shown in Fig. 3. The subjects were required to do the input without looking at the keyboard and while constantly watching the CRT display.

The measuring items in the experiment were the number of answers and the number of errors per unit of time, the quantity of $\alpha$ waves and $\beta$ waves appearing on the electroencephalograms during the tasks, the measured eyestrain before and after the task, and the degree of fatigue generation based on a survey of subjective symptoms of fatigue. One successive work hour in the experiment was 60 minutes, the number of subjects measured per experiment was one person under one condition, and the experiments were conducted at the same time each day to take the circadian rhythm ${ }^{8)-10)}$ and so on into consideration. Also, regarding the environment in the experimental laboratory, the average room temperature was $21^{\circ} \mathrm{C}$ and the average moisture was $48 \%$.
$12 \mathrm{~m}$

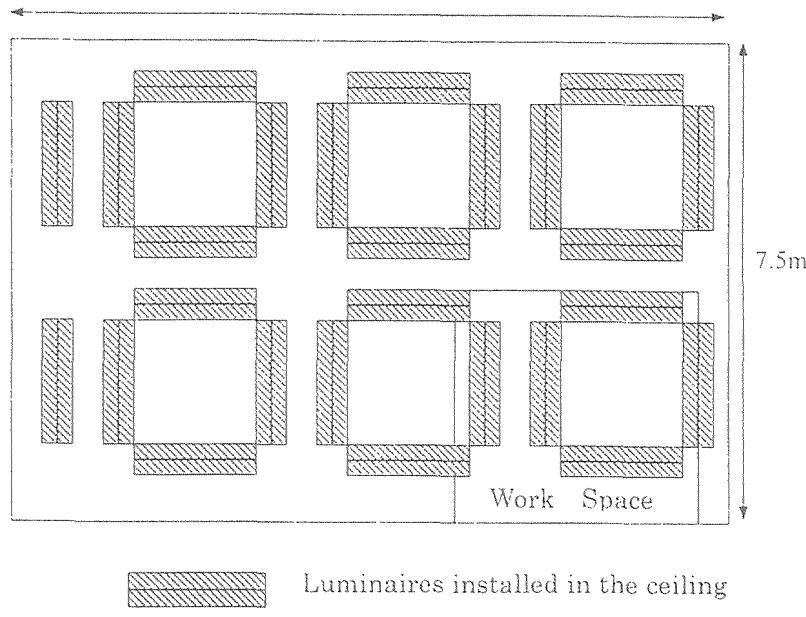

Fig 1 Layout of experiment (Experiment Laboratory)

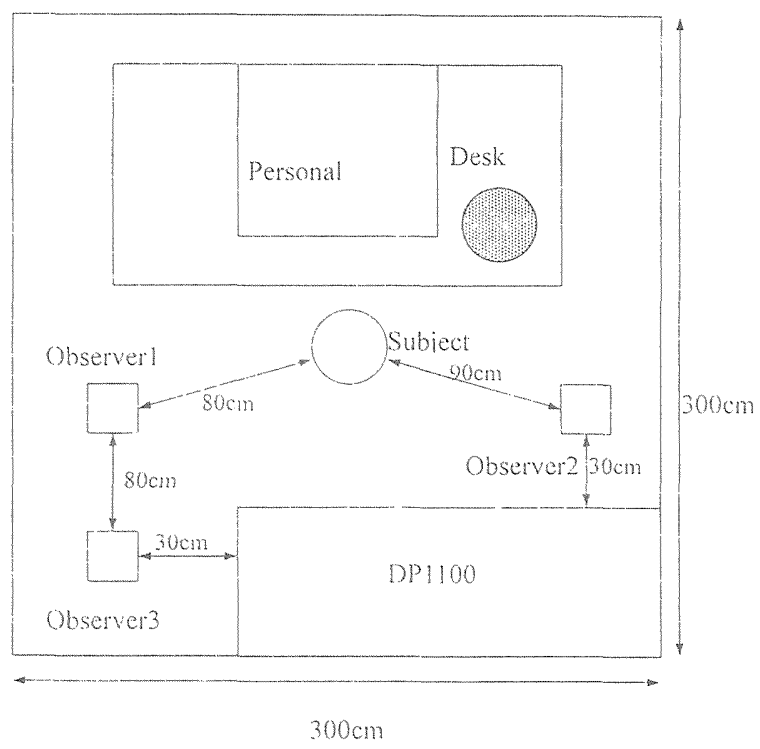

Fig. 2 Layout of experimeny (Working Area)

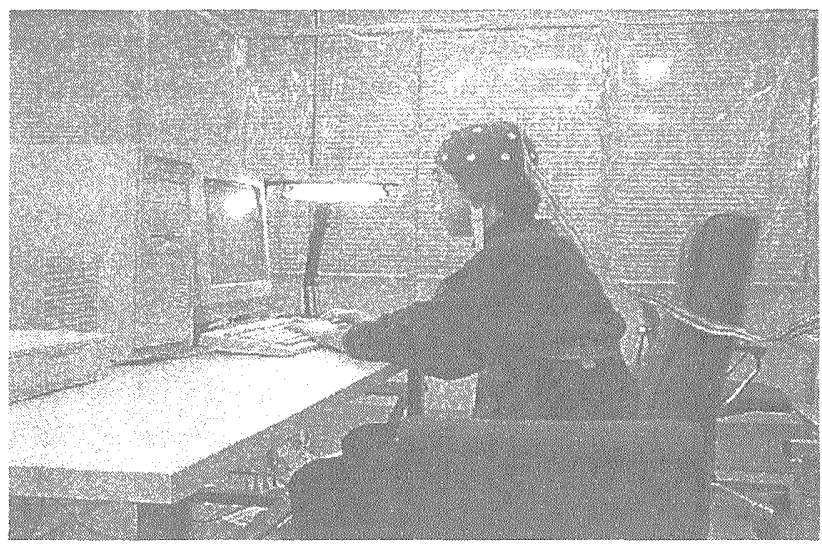

Fig. 3 Experimental situation 


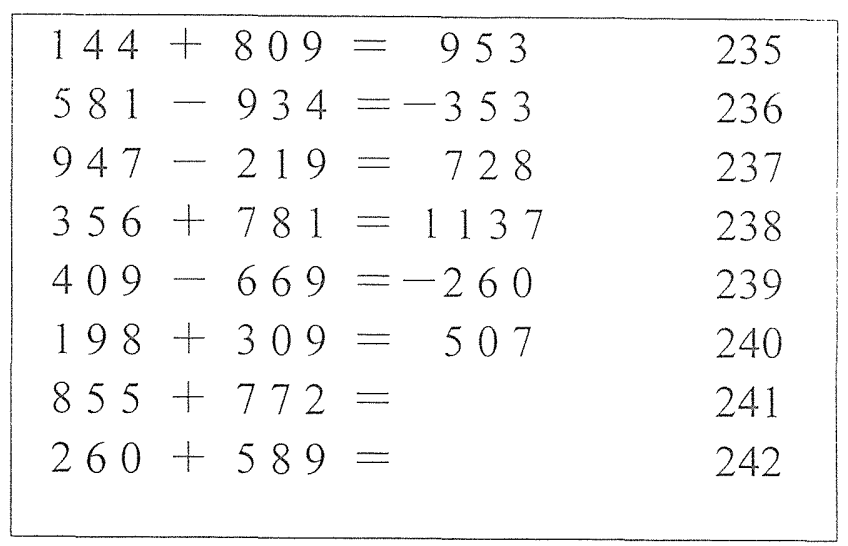

Fig. 4 The display for the experiment

\subsection{Subjects}

The subjects were five healthy males aged from 22 to 24 who were chosen at random. They had a session to become acquainted with the task in the experiment. Also a consideration was made so that the influence of personal differences due to weak sight and color blindness could be minimized by implementing visual abnormality tests before each appointment.

\subsection{Electroencephalographic Measurements}

The number of measuring spots for the electroencephalogram (EEG) was 16 as shown in Fig. 5, which corresponded to the number of electrodes on the electroencephalographic measuring equipment (DP1100). Levels for the nine spots indicated by black circles that have no corresponding electrodes were obtained by supplementary calculation. The total number of spots was 25 . The ears were used for grounding since they do not emit signals.

Although the electroencephalogram is measured by $\alpha$ waves and $\beta$ waves, which are divided in measuring to two each by level of frequency, or $\alpha 1$ and $\alpha 2$, and $\beta 1$ and $\beta 2$, respectively, $\alpha 1+\alpha 2$ are considered simply $\alpha$ wave and $\beta 1+\beta 2$ are considered $\beta$ wave in this report. Also the electroencephalographic measurements were made every seven minutes and were made 9 times, or $(B$ I) for immediately after start of the work, (B II), (B III), (B IV), (B V), (B VI), (BVII), (B VIII), and (B IX) for the end of the task. Each measuring period was about two minutes.

\subsection{Instructions Regarding}

\section{Electroencephalographic Measurements}

It is necessary to carry out the electroencephalographic measurements very scrupulously, and the measurements were made paying attention to the following points:

(1) Subjects were required to slightly open the mouth during the electroencephalographic measurement, since teeth-clenching is picked up as noise.

(2) Subjects were instructed to do the work with a posture so that there is no tension in the neck, since there are

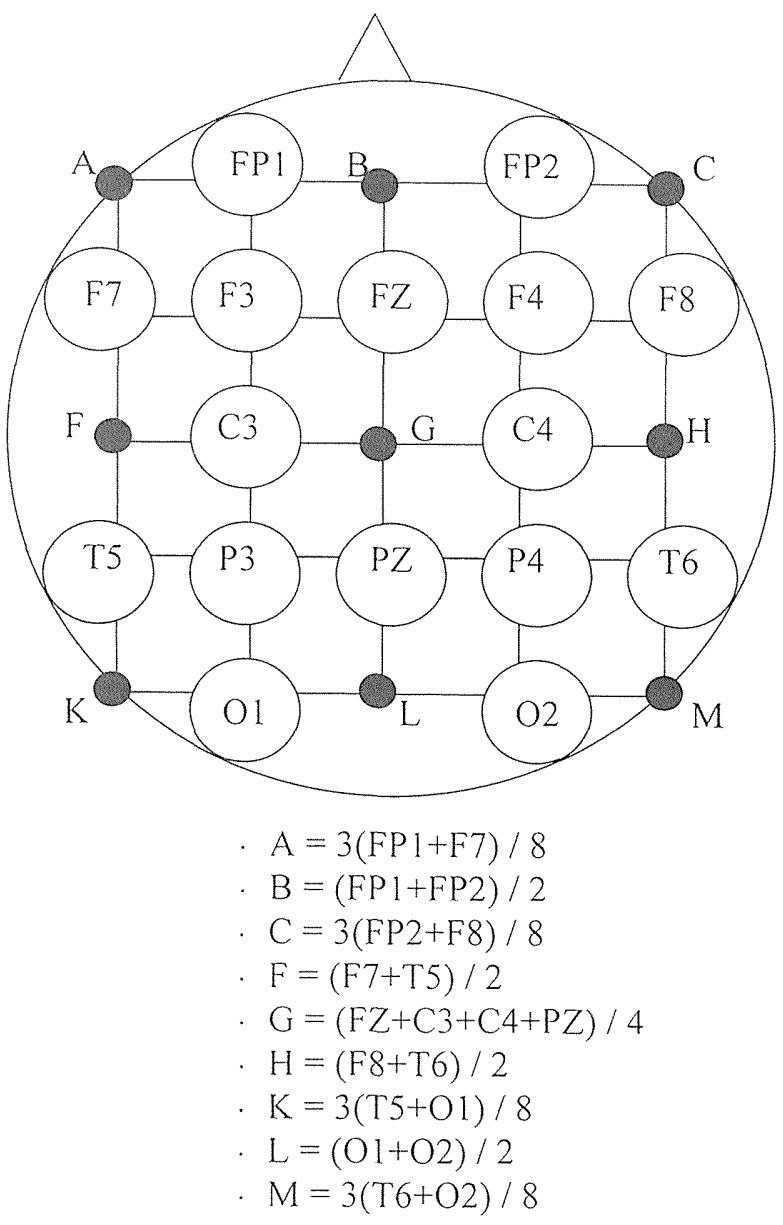

Fig. 5 Spot of the EEG measurement

cases in which the electrical discharges of the neck muscles are picked up at the back of the head by the electroencephalograph.

(3) Subjects were instructed to thoroughly wash the head on the day before the test and not wear hair cosmetics on the day of the experiment, since gel is used to reduce the resistance between the electrodes and the head skin.

(4) Subjects were instructed to sleep well the night before the day of experiment.

\subsection{Lighting Conditions}

The lighting conditions applied for the experiment were six in total. There was the condition in which the fluorescent lamp luminaires were used for ambient lighting (GI) and the condition in which the same was not used (NA). Each of these conditions was further modified by using and not using either one of two kinds of desk lamps, DL1 and DL2, for task lighting, which have different functional levels. The illuminance under each condition is shown in Table 1. In illuminance measuring, the horizontal plane illuminance $\left(I_{h}\right)$ was measured at the center of the keyboard, the surround illuminance $\left(I_{\mathrm{s}}\right)$ was measured at $5 \mathrm{~m}$ in front of it, and the vertical plane illuminance $\left(I_{\mathrm{p}}\right)$ was measured at the center of 
Table 1 Result of illuminance measurement on each working envilonment

\begin{tabular}{|c|c|c|c|c|c|}
\hline & \multirow{2}{*}{$\begin{array}{l}\text { Honizontal } \\
\text { plane } \\
\qquad I_{\mathrm{h}}\end{array}$} & \multirow{2}{*}{$\begin{array}{l}\text { Vertical } \\
\text { Plane } \\
\qquad I_{\mathrm{p}}\end{array}$} & \multirow{2}{*}{$\begin{array}{c}\text { Surround } \\
\qquad I_{\mathrm{s}}\end{array}$} & \multicolumn{2}{|c|}{$\begin{array}{l}\text { Illuminance } \\
\text { ratio }\end{array}$} \\
\hline & & & & $I_{\mathrm{p}} / I_{\mathrm{h}}$ & $I_{s} / I_{h}$ \\
\hline $\mathrm{NA}$ & 34.6 & 13 & 34.6 & 0.376 & 1.000 \\
\hline NA+DL1 & 645 & 240 & 34.6 & 0.372 & 0.054 \\
\hline $\mathrm{NA}+\mathrm{DL} 2$ & 725 & 230 & 34.6 & 0.317 & 0.048 \\
\hline GI & 1550 & 685 & 1550 & 0.442 & 1.000 \\
\hline GI+DL1 & 2040 & 895 & 1550 & 0.439 & 0.760 \\
\hline $\mathrm{GI}+\mathrm{DL} 2$ & 2140 & 887 & 1550 & 0.414 & 0.724 \\
\hline
\end{tabular}

Table 2 The types of desk lamps used in this experiment

\begin{tabular}{|c|c|c|}
\hline $\begin{array}{l}\text { The type of desk } \\
\text { Lamp used in this } \\
\text { experiment }\end{array}$ & DL1 & DL2 \\
\hline Desk lamp & BS3531K & $\mathrm{BSO02K}$ \\
\hline Light source & $\begin{array}{l}\text { Three-band fluorescent } \\
\text { lamp, } 27 W \\
\text { Model:PPL27EX-N }\end{array}$ & $\begin{array}{l}\text { High Color renering } \\
\text { fluorecent lamp, } 27 \mathrm{~W} \\
\text { Modet:FP27ANX }\end{array}$ \\
\hline Spectrum type & Trichromatic & Continuous spectrum \\
\hline $\begin{array}{l}\text { Luminous flux of lamp } \\
\text { (Im) }\end{array}$ & 1800 & 1170 \\
\hline Color temperature $(\mathrm{k})$ & 5000 & 5500 \\
\hline $\begin{array}{l}\text { Color rendering index } \\
\text { (CRI) }\end{array}$ & 84 & 95 \\
\hline Illuminance & $\begin{array}{l}\text { Average illuminance : } \\
\quad 579(\mathrm{~lx}) \\
\text { llluminance uniformity } \\
\text { ratio }(\max / \mathrm{min}) \\
\quad 5.00\end{array}$ & $\begin{array}{l}\text { Average illuminance : } \\
\quad 664(\mathrm{~lx}) \\
\text { Illuminance unifomity } \\
\text { Ratio }(\max / \mathrm{min}) \\
\quad 2.97\end{array}$ \\
\hline
\end{tabular}

the display. Also, the horizontal plane illuminance and surround illuminance were measured at $75 \mathrm{~cm}$ above the floor.

\subsection{Luminaires Used}

The properties of the two kinds of desk lamps used for localized lighting in this experiment are shown in Table 2. The illuminance is shown by the average illuminance and the uniformity ratio of illuminance in the primary zone is based on the Standard of the Residential Mllumination of the Illuminating Engineering Society of North America.

\subsection{Eyestrain Measurement}

The distance of the adjusted near points, tension period, and relaxation period were measured before and after this experiment using the Accomed Polirecorder (HS-9E).

Measurement of the distance of the adjusted near point was done by the method of showing the visual target of the near point to the subjects and having it go away repeatedly. The subjects were instructed to respond by immediately pushing the response switch when the split at the center of the
Landolt ring is seen while it is moving. After it was confirmed that the subjects correctly understood the instructions during the practice of perception and response through the demonstration of the visual target repeated two to three times, the recording was started to get the data. The data was measured ten times and the average was used.

For the measurement of the tension period and the relaxation period, the near point target and remote point target were set at the near point and the remote point respectively, and, simultaneously with the start of measuring they alternately flashed with an interval of five seconds. Subjects saw the targets dimly at the moment of switching of the target, but they began to be able to see the targets clearly after a while. They were instructed to respond by immediately pushing the response switch when they saw the targets. After it was confirmed that the subjects correctly understood the instructions through two or three repetitions of the exercise, the recording was started to get the data. The data was measured for five times each and their average was used. By the way, although the number of measurements in this procedure was five times, this was equivalent to measuring ten times in total for the adjusting time, since the tension period and relaxation period were measured successively and alternately.

\subsection{Survey of Subjective Symptoms of Fatigue}

In order to check the level of the fatigue generation after completion of tasks under each illumination condition, the subjects were required to fill out the "Survey of Subjective Symptoms" 11) 12) edited by the Japan Society for Occupational Health, Technical committee for Industrial fatigue (Sangyou Hiro Kenkyukai). In the survey of the subjective symptoms of fatigue, temporal changes are the subject of inquiry, as seen by its procedures, in which a person indicates his subjective symptoms when first completing the form and that he is requested to fill out the form again after a while. Because of this, it has been widely used as a method to survey the feeling of fatigue.

The feeling of fatigue was categorized into three types for this survey, and the elements of each type can be surveyed. For example, Group I consisted of 10 items characterized by sleepiness and dullness such as "felt heavy in the head, yawned, and felt sleepy" that are related the complaints of common fatigue, Group II consisted of 10 items characterized by reduction of drive accompanied by difficulties in concentration and attention such as "could not get an idea into shape, frustrated, and could not concentrate" that are related to complaints of psychological symptoms, and Group III consisted of 10 items characterized by unpleasant feelings in a portion of the body such as "had headaches, felt stiff in the shoulders, and had a pain in the waist" that are related to complaints of psychosomatic symptoms in specific portions of the body. Subjects were required to complete the questionnaire before and after the task in each experimental 
condition, and the results were compared relative to the experimental conditions.

\section{Results and Discussion \\ 3.1 Productivity}

The results of the average number of total answers offered and the average ratio of incorrect answers of all the subjects per experimental condition are shown in Fig. 6 and 7, respectively. Table 3 shows the result of the 2-way ANOVA dispersion analysis which was done using the results of the number of answers shown in Fig. 6 in order to see the influence in the number of total answers by two factors: (A) the work condition, and (B) the elapsed time by every three minutes, assuming that the five subjects were a repetitive factor $(R)$ or, in other words, a block element ${ }^{13)}$. Significant differences were recognized based on Table 3 at the 1\% probability level on factor $A$ and $R$ and at the $5 \%$ probability level on factor B. Then, a $t$ test was implemented by dividing the working time by six per every ten minutes in order to check the influence of the elapsed time on the total number of answers, but no uniform view was obtained. It is considered that this is attributable to the differences in the subjects in the pace allocated to the tasks, and so on. Next, since it is considered that a significant difference is noted in the repetitive factor $(R)$ because of the large influence of the individual differences, examination of the differences in the average values, which were handled as corresponding to each other, was implemented taking this point into consideration. This examination is, regarding the case of two sets of data that have correspondence and make sets as in this experiment, to make it independent when there is a difference in a combination of data or

$d_{i}=X_{A i}-X_{B i}$ (where, $1 \leq i \leq n, n=$ the number of data combinations)

and to ask if the population mean $\mu_{\mathrm{d}}$ of $d_{i}$ is 0 or not when there is no difference between $A$ and $B$.

As a result of the 2-way ANOVA dispersion analysis, the number of answers showed an increase in the environment with a low surround illuminance ratio as well as in the environment with a low vertical plane illuminance ratio. Also, it was found that the surround illuminance ratio in such situation was about 0.05 . Also, a statistically significant difference between the cases with and without the ambient lighting was not noticed, but the significant difference at the $1 \%$ probability level was noted with the task lighting, and it was found that the work efficiency got higher in the sequence of no task lighting, desk lamp 1, and desk lamp 2. Next, the results of the 2-way ANOVA dispersion analysis similar to the previous description using the results of incorrect answer ratio, as shown in Table 4, are shown in Fig. 7. From Table 4, the significant difference at the $1 \%$ probability level was noted with the factors $A$ and $R$. Then, in consideration of paying attention to the influence of the individual differences similar to the previous description, an examination was done on the difference in the averages in which correspondences were given. As a result, a significant difference was noted in the environment of low surround illuminance ratio and it was noted that the incorrect answer ratio decreased in the environment not using the ambient lighting.

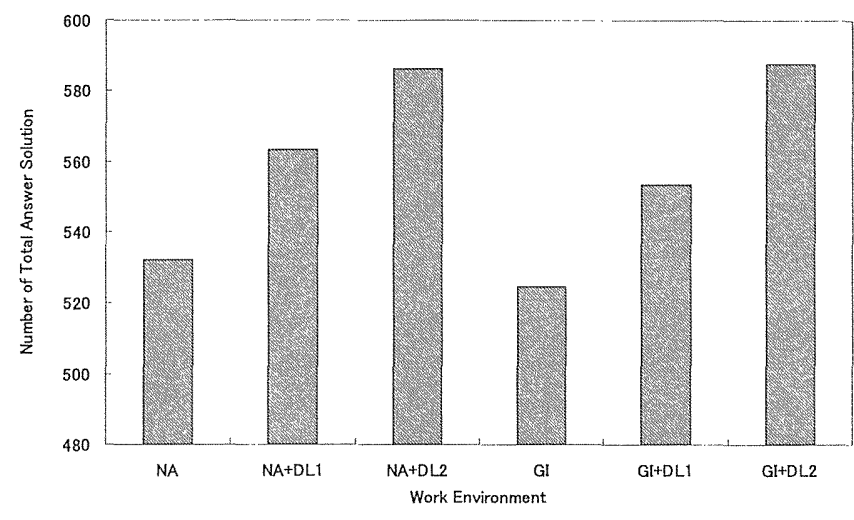

Fig. 6 Results of the number of total answer solutions

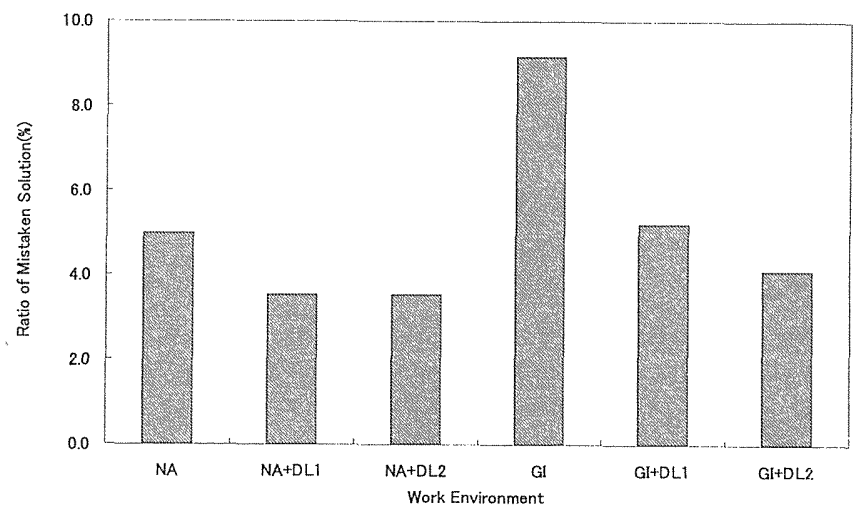

Fig. 7 Results of the ratio of mistaken solutions

Table 3 2-way ANOVA (Number of answer solutions)

\begin{tabular}{|l|rr|r|r|r|}
\hline Factor & $\begin{array}{l}\text { Degrees } \\
\text { freedom }\end{array}$ & Variation & $\begin{array}{l}\text { Unbiased } \\
\text { Variance }\end{array}$ & $\begin{array}{l}\text { Dispersion } \\
\text { ratio }\end{array}$ \\
\hline (A) & 5 & 881.080 & 176.216 & $20.647^{* * *}$ \\
\hline (B) & 19 & 303.607 & 15.979 & $1.872^{*}$ \\
\hline A*B & 95 & 830.053 & 8.737 & 1.391 \\
\hline (R) & 4 & 7383.823 & 1845.956 & $216.285^{* * *}$ \\
\hline Error & 473 & 4062.577 & 8.535 & \\
\hline Sum & 599 & 13461.140 & & \\
\hline
\end{tabular}

Table 4 2-way ANOVA (Ratio of mistaken solutions )

\begin{tabular}{|l|rr|r|r|r|}
\hline Factor & $\begin{array}{l}\text { Degrees } \\
\text { freedom }\end{array}$ & Variation & $\begin{array}{l}\text { Unbiased } \\
\text { Variance }\end{array}$ & \multicolumn{1}{l|}{$\begin{array}{l}\text { Dispersion } \\
\text { ratio }\end{array}$} \\
\hline (A) & 5 & 2619.666 & 523.933 & $20.608^{* *}$ \\
\hline$(B)$ & 19 & 501.448 & 26.392 & 1.038 \\
\hline A*B & 95 & 2335.822 & 24.588 & 0.967 \\
\hline$(\mathrm{R})$ & 4 & 5806.341 & 1451.585 & $57.096^{\text {*i* }}$ \\
\hline Error & 476 & 12101.612 & 25.424 & \\
\hline Sum & 599 & 23364.889 & & \\
\hline
\end{tabular}




\subsection{Electroencephalogram}

The evaluation method regarding the electroencephalogram during tasks in this experiment is based upon the following way of thinking by Nakamura et alia ${ }^{14)}$ and Nagamachi ${ }^{15)}$ : "In the state in which one is concentrating in something, the level of the $\alpha$ wave appearance becomes lower due to the $\alpha$ wave suppressing reaction. When the $\alpha$ wave re-appears after it is disappeared, it indicates a reduction in the consciousness level. Also, although the level of the $\beta$ wave appearance increases in the state of psychological frustration and strain, it occasionally increases in the state of concentration."

The average of the appearance level of electroencephalographic waves ( $\alpha$ wave, $\beta$ wave) during the tasks for all the subjects under each of the experimental condition is shown in Fig. 8 and Fig. 9. The results of the 2-way ANOVA dispersion analysis on the factors of A, work condition, and $\mathrm{B}$, elapsed time using the results in Fig. 8 and Fig. 9, are shown in Table 5 and Table 6. The electroencephalogram during tasks was divided by nine as described before. From Table 5 and Table 6, the significant difference at the $1 \%$ probability level was noted in all factors of $\mathrm{A}, \mathrm{B}$, and $\mathrm{R}$. Hence, in order to check the influence of individual difference, which is a consideration similar to the previous description, differences in the corresponding averages were examined. As a result, the tendency of a reduction in the level of the $\alpha$ wave was noted in the environment of low vertical plane illuminance ratio in conditions with and without the ambient lighting and, from Fig. 8 , in the case of the task lighting being used and in the environment of a low surround illuminance ratio. It was found that the surround illuminance ratio was about 0.05 at that time.

Next, it was noted, from Fig. 9, that the $\beta$ wave that shows frustration decreased in the environment with a low surround illuminance ratio coupled with a low vertical plane illuminance ratio. From the above, it was found that the $\beta$ wave level is reduced in the environment not using the ambient lighting and with the use of the task lighting alone, especially with desk lamp 2.

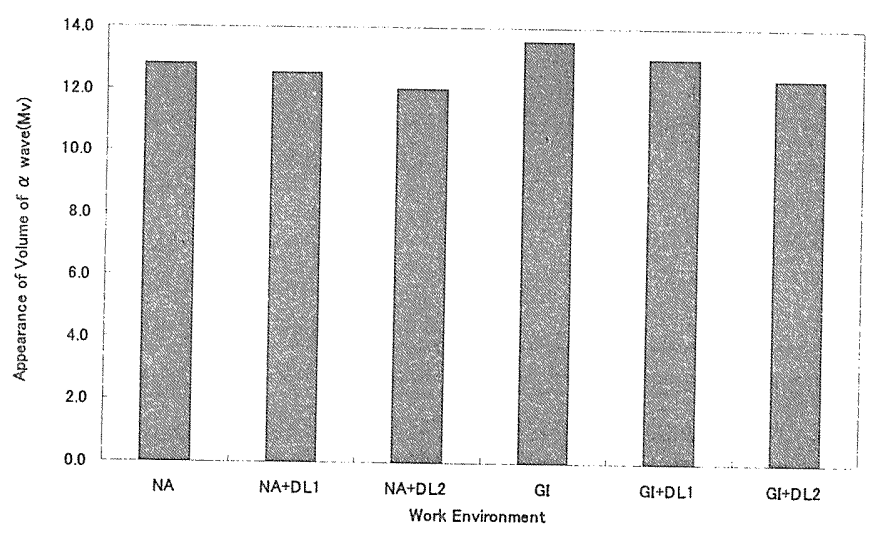

Fig. 8 Results of appearance levels of $\alpha$ waves

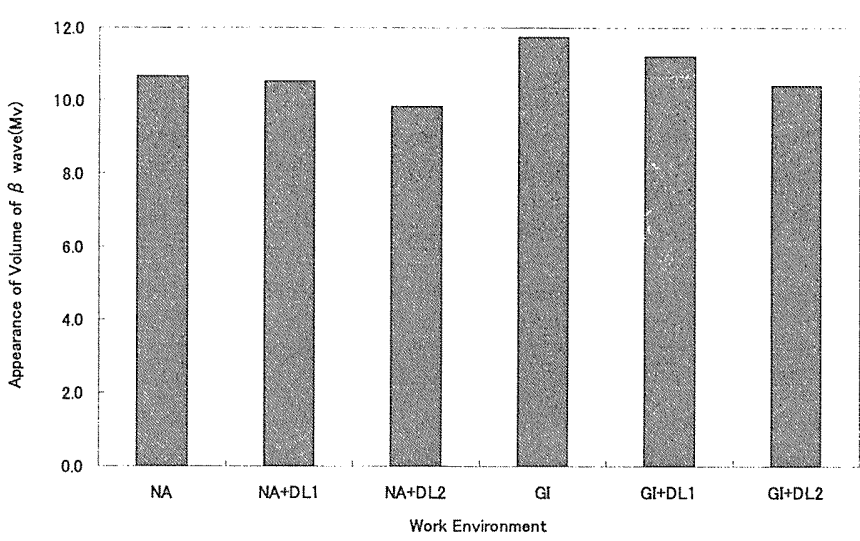

Fig. 9 Results of appearance levels of $\beta$ waves

Table 5 2-way ANOVA (Appearance Levels of $\alpha$ wave)

\begin{tabular}{|l|r|r|r|r|}
\hline Factor & $\begin{array}{l}\text { Degrees } \\
\text { freedom }\end{array}$ & of & \multicolumn{1}{l|}{$\begin{array}{l}\text { Unbiased } \\
\text { Variance }\end{array}$} & \multicolumn{1}{l|}{$\begin{array}{l}\text { Dispersion } \\
\text { ratio }\end{array}$} \\
\hline$(\mathrm{A})$ & 5 & 65.730 & 13.146 & $5.862^{* *}$ \\
\hline$(\mathrm{B})$ & 8 & 74.315 & 9.289 & $4.142^{* *}$ \\
\hline A*B & 40 & 48.104 & 1.203 & 0.536 \\
\hline (R) & 4 & 7403.095 & 1850.771 & $825.270^{* *}$ \\
\hline Error & 212 & 475.737 & 2.243 & \\
\hline Sum & 269 & 8066.681 & & \\
\hline
\end{tabular}

Table 6 2-way ANOVA (Appearance Levels of $\beta$ wave )

\begin{tabular}{|l|rr|r|r|r|}
\hline Factor & $\begin{array}{l}\text { Degrees } \\
\text { freedom }\end{array}$ & Variation & $\begin{array}{l}\text { Unbiased } \\
\text { Variance }\end{array}$ & \multicolumn{1}{l|}{$\begin{array}{l}\text { Dispersion } \\
\text { ratio }\end{array}$} \\
\hline (A) & 5 & 98.846 & 19.769 & $12.955^{* *}$ \\
\hline (B) & 8 & 32.973 & 4.122 & $2.701^{\text {*** }}$ \\
\hline A*B & 40 & 24.624 & 0.616 & 0.403 \\
\hline (R) & 4 & 1063.917 & 265.979 & $174.303^{\text {** }}$ \\
\hline Error & 212 & 323.503 & 1.526 & \\
\hline Sum & 269 & 1543.863 & & \\
\hline
\end{tabular}

3.3 Asthenopia Fatigue and Subjective Symptoms Variances of the adjusted near point distance, tension period, and relaxation period after the tasks, assuming that those before the tasks as $100 \%$, are shown in Fig.10. It is known from Fig. 10 that there is a tendency for the reduction in the variances in the case with the surround illuminance ratio of about $0.05 \%$, or, in other words, when the surround illuminance ratio is lower. This phenomenon is considered to be attributable to the conditions of "with or without" ambient lighting. Next, the variances of the complaint ratio of all the subjects before and after the tasks in the survey of subjective symptoms of fatigue is shown in Fig. 11 by group. It is important to evaluate the concentration level for the tasks and the degree of fatigue under each lighting condition since the objective task was static work in this experiment. From Fig. 11, it is known that the variances in the complaint ratio 


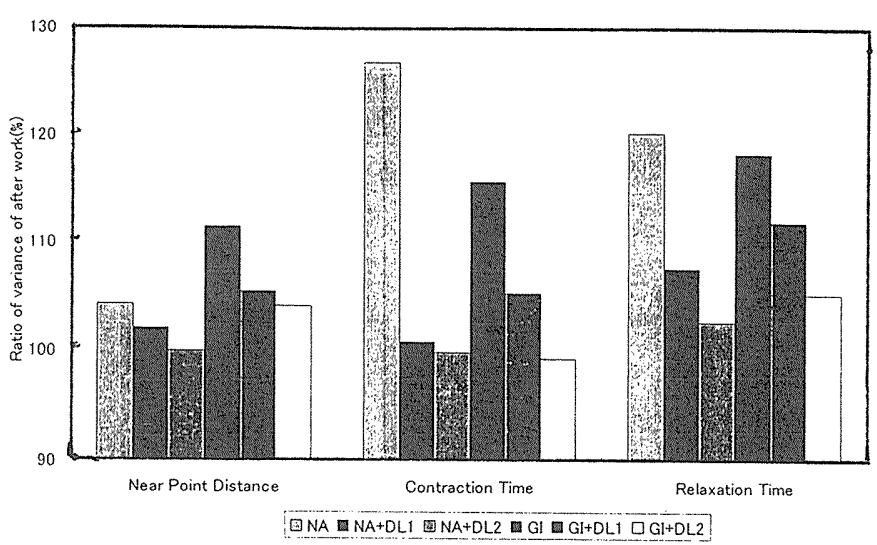

Fig. 10 Results of fatigue of the astheonopia measurement

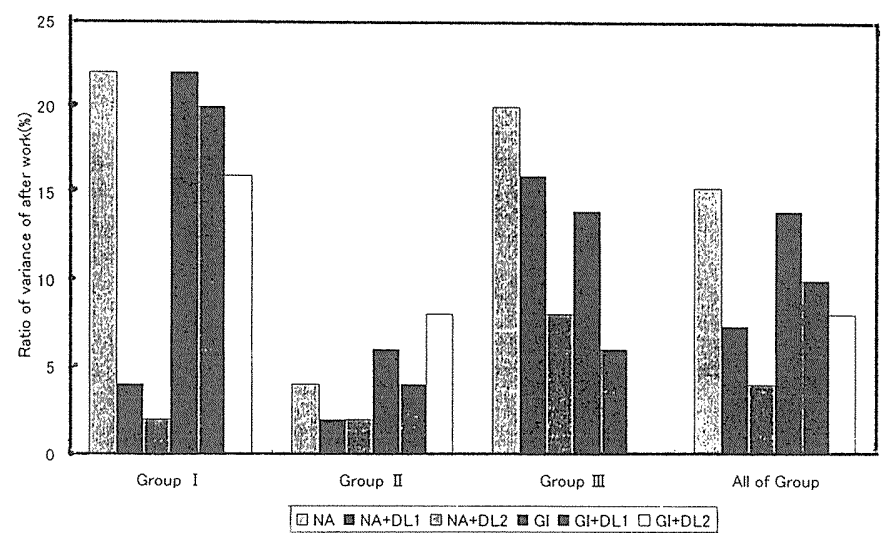

Fig 11 The ratio of variance on survey of subjective symptom

in Group I and Group II decrease in parallel with a decrease in the surround illuminance ratio. This is a tendency similar to the asthenopia fatigue and it can be said that the level of the fatigue generation is reduced in parallel with a reduction in the electroencephalogram appearance level during the tasks. That is to say, it is considered that the environment with task lighting alone is effective for concentration and psychological stability.

\section{Summary of Discussion}

Discussion in the above can be summarized that the condition of the surround illuminance of about 0.05 is the most effective in the environment in which a desk lamp for task lighting is used, in light of the productivity that is defined by the work efficiency (number of answers in the calculation work) and the work quality (error ratio in the calculation work).

In view of the electroencephalogram, the asthenopia fatigue measurement, and the survey of subjective symptoms that indicate workload, the work environment that has the task lighting with the surround illuminance ratio of about 0.05 shows a tendency to reduce the level of fatigue emergence in the workers and, thus, it can be expected that it has an outstanding effect on concentration and psychological stability.

\section{Conclusion}

This study was to clarify the influence of ambient lighting and task lighting, which are the factors for designing a VDT work system, on the workers' productivity and workload and to point out factors for an appropriate work environment for VDT operations.

As a result of this study, the following facts are pointed out, although they are constrained by the experimental conditions of this experiment:

(1) In the task lighting, its effect can be conspicuously noted with a surround illuminance ratio of about 0.05 .

(2) In the case of the same surround illuminance ratio, a greater effect can be noted under the lower vertical plane illuminance ratio.

These results suggest that they are effective for VDT tasks mainly associated with thinking. Therefore, it is considered that they can be applied to the practical tasks as the environmental factors for the operations of similar kinds of work.

\section{References}

(1) Hosokawa, Nishiyama, Nakaseko, and Tainaka: "Introduction to VDT Tasks" in Japanese, Labor Standard Survey Group, pp.67-68, pp. 208-211, (1984)

(2) National Research Council, Translator Sadao Sugiyama: "VDT Work and Human Beings" in Japanese, Japan Publication Service, pp. 191-197 (1987)

(3) P. T. Stone: "Visual Perception and Lighting for VDT Users, OA Syndrome - Health Hazard due to VDT Tasks" in Japanese, Editor Brian Pierce, Keigaku Shuppan, pp. 79-90 (1986)

(4) Sakagami, Akashi, Umeno, and Yagi: "Re: Relationship between Concentration of Workers and Lighting Environment" in Japanese, Journal of IEIJ, 81-5, pp. 385-391 (1997)

(5) Hoshino, Shigeyoshi, Ohgimoto, and Matsuda: "Study of Physiological Propertiies of Various Lighting" in Japanese, National Conference of IEIJ, pp. 107-108, (1992)

(6) Tazaki, Ohyama, and Hiwatari* "Treatment of Visual Information" in Japanese, Asakura Shoten, p. 372 (1979)

(7) Gu, and Sakamoto: "Study on the Evaluation of Eye Fatigue Due to Fixed Seeing of Flicker" in Japanese, Journal of Japanese Human Engineering Society, 32-2, pp. 87-97 (1996)

(8) Ohshima, and Ohkubo: "Human Engineering" in Japanese, Asakura Shoten, pp. 107-111 (1989)

(9) Hashimoto, and Endoh: "How to See Function of the Living Body" in Japanese, Hito-to-Gijyutsu Sha, pp. 11-18 (1973) 
(10) Kiyohisa Takahashi and Yasurou Takahashi: "Circadian Rhythm" in Japanese, Chuugai Igaku Sha, pp. 61-75 (1980)

(11) Ogi: "The Moderns and Fatigue" in Japanese, Kinokuniya Shoten, pp. 99-105 (1983)

(12) Yoshitake: "Life and Fatigue of the Japanese" in Japanese, Labor Science Research Center Publication Dept., pp. 3-9 (1983)
(13) Washio: "Introduction to Linear Programming" in Japanese, Japan Standard Association, pp. 89-96 (1974)

(14) Nakamura, and Sakata: "Science of Brain II" in Japanese, Asakura Shoten, pp. 4-6 (1983)

(15) Nagamachi: "Contemporary Human Engineering" in Japanese, Asakura Shoten, pp. 58-60 (1986) 